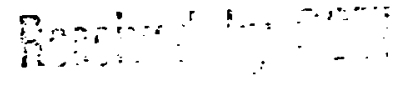

FEB i 2 ids

\title{
A Versatile Laser Glass Inspection and Damiage Testing Facility
}
J. E. Marion
G. J. Greiner
J. H. CampbelT
P. H. Chaffee
J. S. Hildum
J. Z. Grens
C. L. Weinzapfel
S. M. Winfree
D. Milam

This paper was prepared for submittal to

Boulder Damage Symposium

Boulder, Colorado

October 28-30, 1985

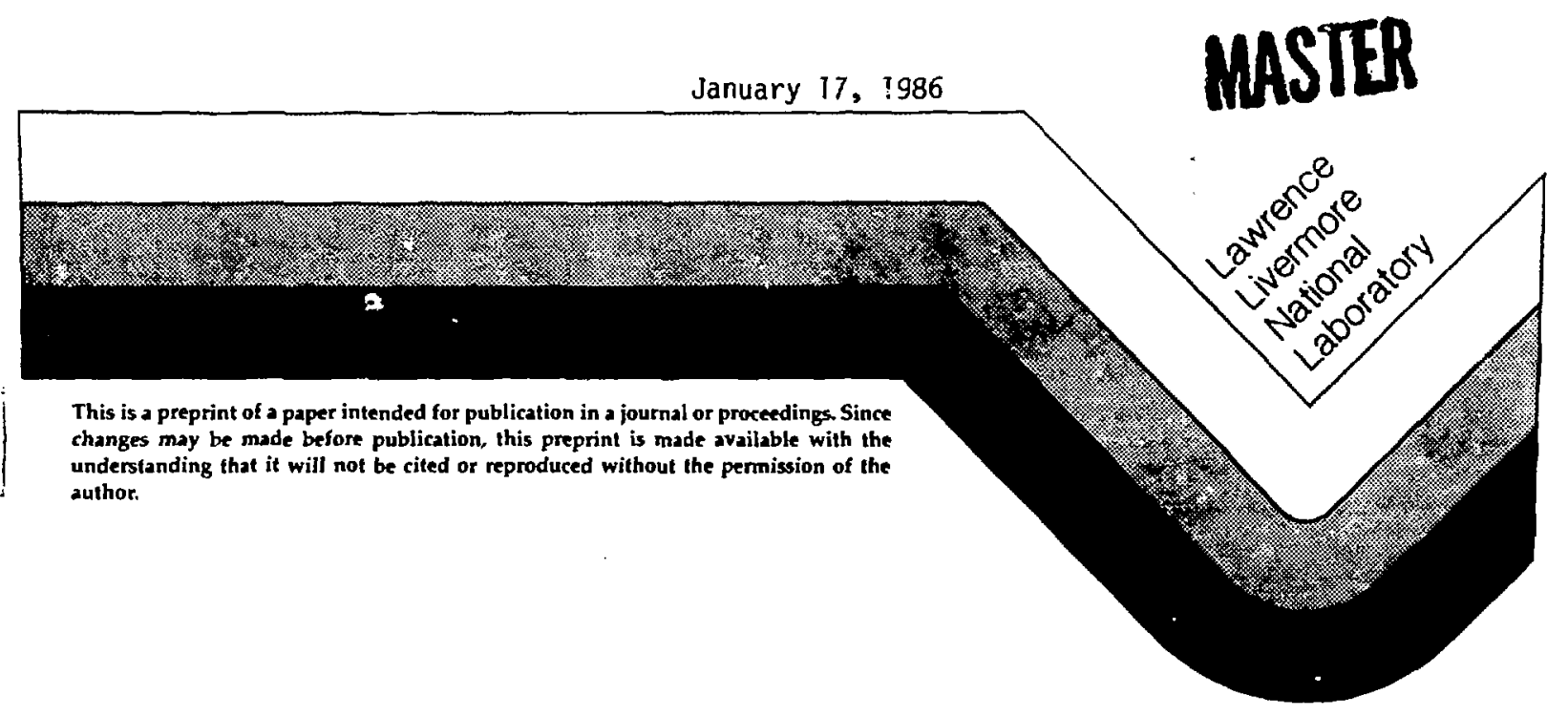




\title{
A Versatile Laser Glass Inspection and Damage Testing Facility*
}

J. E. Marion, G. J. Greiner, J. H. Campbell, P. H. Chaffee, J. S. Hildum, J. Z. Grens, C. L. Weinzapfel, S. M. Winfree and D. Milam Lawrence Livermore National Laboratory University of California

P. O. Box $5508, L-490$

Livermore, California 94550

\begin{abstract}
Most glass optical components for high power lic ers are melted and homogenized in platinum-lined crucibles leading to the potential presence of microscopic platinum inclusions. In situations where laige optics are exposed to high laser fluences, a significant problem can be creat $\lambda$ by an extremely low density of inclusions, as low as one per component. Previously, direct visual examination or optical microscopy was used to inspect for these particles, limiting reliable detection to inclusiors greater than $10 \mu m$ diameter. Unfortunately, much smaller inclusions can initiate damage in modern lasers operated at high fluences.

A test facility is described which detects small opaque inclusions in large transparent components by using a commercial laser which delivers high energy pulses to the test sample at moderate frequency in $\rightarrow$ small diameter beam. The sample is automatically scanned such that each point in the volume is irradiated with ten pulses at twice the inclusion damage threshold--an amount sufficient to cause visible damage at inclusion sites. This approach permits detection of opaque inclusions in the parts per trillion and lower concentration range. The specifics of the device design, and its performance are discussed in the context of automatic inclusion inspection and mapping in large laser optics.
\end{abstract}

*Work performed under the auspices of the U.S. Department of Energy by Lawrence Livermore National Laboratory under Contract No. W-7405-ENG-48.

$4870 \mathrm{~T}$

DISCLAIMER

\begin{abstract}
This report was prepared as an account of work sponsored by an agency of the United States Government. Neither the United States Government nor any agency thereor, nor any of their employes, makes any warranty, express of implied, or assumes any legal liability or responsbility for the sceuracy, completenest, or uncfulness of any information, apparatus, product, or process dieclosed, of represents that its use would not infringe privately owned rights. Reference herein to any specific commercial product, process, of service by trede nuone, trademark, ranufacturer, or otherwive does not necestarily constitute or imply its endorsement, recommendation, or favoring by the United States Government or any efency thereor. The views and opinions of authors expressed herein do mol mecesearily state or refloct thone of the United States Government or any azency thereof.
\end{abstract}




\section{Introduction}

Modern fusion research lasers and proposed defensive laser weapons use very large optics which aro exposed to high laser fluences. 1 If present, opaque microscopic inclusions cause unacceptable damage. A simple device for performing large scale inspection of optical components for the presence of inclusions is described. Our present application requires a system capable of rapid and reliable inspection of Nd:phosphate glass samples for inclusions which absorb at $1.06 \mu \mathrm{m}$, such as platinum and carbon. The samples include finished amplifier disks, ranging in volume up to about 10 liters, as well as numerous test samples. The size of the inclusions which must be located extend into the sub-micron region--a territory in which conventional optical microscopy is ineffective. Light scattering methods are unwieldy because bubbles, surface imperfections and dust are indistinguishable from inclusions even when the sample is of high optical quality. Signals from these imperfections can swamp the signals of interest because the inclusion number density is quite $10 \mathrm{w}$, in the $10^{-4} / \mathrm{cm}^{3}$ range.

We adopt a destructive technique for locating inclusions as the only reliable method available. A commercial Q-switched YAG laser (JK Model HY 750) gives a focussed beam $2 \mathrm{~mm}$ diameter on the sample which is scanned in $x$ and $Z$ directions by a commercial stage drive (Daedal Models 47215 LH and MLH, Fig. 1). In order to assure adequately large damage sites at each inclusion (to facilitate subsequent optical inspection) each site in the sample is irradiated at normal incidence with ten shots; each above $10 \mathrm{~J} / \mathrm{cm}^{2}$. This fluence corresponds to twice the damage 
threshold for platinum inclusions in glass at the $8 \mathrm{~ns}$ pulsewidths used here. ${ }^{2}$ In practice, the device is capable of scanning a $46 \mathrm{~cm}$ aperture phosphate glass amplifier disk (7000 $\mathrm{cm}^{3}$ volume) in about four hours using ten shots per site. Reducing the number of shots proportionately reduces the scan time. The optical examination of the damaged disk takes an additional hour or so depending on the number of damage sites which must be characterized and mapped.

\section{Device Description}

The device is located in a class 1000 clean room in order to avoid dust contamination and subsequent damage to the device optics as well as the test sampie. The laser is quite stable with better than $99 \%$ of the shots within $1 \%$ of the mean shot energy. The beam profile is adequately uniform to insure that the sample is irradiated at the desired fluence (Fig. 2). The output energy is $800 \mathrm{~mJ}$ at $8 \mathrm{~ns}$ pulsewidth and $20 \mathrm{~Hz}$ PRF. The slightly diyarging $8 \mathrm{~mm}$ diameter output beam is approximately collimated by a five meter lens and directed toward the sample by high power dielectric-coated mirrors. It is then focussed by a two meter positive lens into a mildly converging beam. A collinear HeNe alignment beam is introduced before the positive lens to aid in sample positioning. A beam splitter (with the front surface anti-reflection coated) is located after the two meter lens, and a calorimeter monitors the second surface reflection as a continuous check of laser performance. After the beam splitter, the laser beam, now $2 \mathrm{~mm}$ in diameter, strikes the sample which is mounted on a $X-Z$ motor driven stage. 
The laser and the stage drive are controlled by a laboratory computer (Hewlett Packard 9816S), interfaced through a general purpose data acquisition control unit (HP 3421A). If dust or damage occurs upstream, leading to a degradation in the laser energy, the test is interrupted by the computer monitoring the calorimeter. Automatic shut off of the laser and stage drive can also occur if the sample reaches position limit triggers, or if there is a high laser cooling water temperature.

The use of the computer also offers the possibility of real time inclusion mapping. When irradiated, the damaging inclusions give a distinct optical signal associated with plasma emission. This signal can be readily detected by focussing onto a photodiode array. This information is combined with $x-2$ position coordinates to give an inclusion map. A) though the detection system has been demonstrated, ${ }^{3}$ it is not yet sufficiently reliable to replace optical inspection. Incerporation of this mapping option will reduce the inspection time by an order of magnitude because only one shot at each site will be required. The post fiortem optical inspection will also be eliminated along with its inherent operator subjectivity.

\section{Device Applications}

We believe that this facility offers a unique capability in materials damage assessment. Prior damage testing has generally fallen into one of two categories. Previously, small $\left(\mathrm{mm}^{2}\right.$ or smaller) beams at high fluences were used to test several spots on the sample, in conjunction with a statistical treatment of the data. ${ }^{4}$ The limitations of that method in situations where the damaging entities have a very low spatial density are obvious. A second approach uses a research tool such as the 
Nova laser to give high fluences over an entire area in single shots, but at very low repetition rate. ${ }^{5}$ Aside from the expense of the latter method, our new device is fastei and less cumbersome. Large optics can now be quickly a.ld reliably inspected for inclusion volume concentrations in the parts per quadrillion range $\left(10^{15}\right.$ ) (i.e., several one micron diameter inclusions in a $7000 \mathrm{~cm}^{3}$ optical component.)

A further advantage of this testing device is its ability to rapidly perform multiple shot damage characterization on inclusions that have been carefully analyzed prior to testing. Damage growth rate data on single inclusions subjected to ten thousand shots or more can be obtained readily, helping to relieve the paucity of information in that area.

Finally, it has not escaped the attention of the authors that this device has useful applications in other fields of materials science and chemistry, for example, in any application in which small concentrations of microscopic contaminants must be detected. In principle, any laser wavelength may be used where the samples are reasonably transparent. The primary requirement is that the microscopic inclusions or defects have a higher absorption than the surrounding matrix at the laser wavelength.

\section{Summary}

Our requirement for rapid inspection of large optics for the presence of microscopic inclusions has led us to construct a simple damage device using a Q-switched YAG laser and a computer controlled $X-Z$ motor driven stage. Each point in the volume of the test sample receives ten pulses at twice the damage threshold, permitting straightforward post mortem visual determination of inclusion spatial density. An automatic detection scheme, in development, :i11 permit automatic mapping. 
$-6-$

In addition to automated inspection, straightforward damage growth characterization to high shot numbers is being pursued. This information is of interest for assessing optical component reliability both for fusion research lasers as well as defensive laser weapon systems. 


\section{References}

1. Laser Program Annual Report, Lawrence Livermore National Laboratory, Livermore, CA, Eds. M. L. Rufer, P. W. Murphy, 1984.

2. R. P. Gonzales and D. Milam, "Evolution during multiple-shot irradiation of damage surrounding isolated platinum inclusions in phosphate laser glass", elsewhere in these proceedings.

3. J. E. Marion, unpublished.

4. Statistical aspects of laser-induced damage were first treated in: M. Bass and H. H. Barrett, "The probability and dynamics of damaging optical materials with lasers". Proceedings of Damage in Laser Materials: 1971, NBS Spec. Pub. 356, pp. 76, issued Nov. 1971. The first treatment of the probability of encountering isolated defects with a small test beam was: L. G. deShazer, B. E. Newnam and K. M. Leung. "The role of coating defects in laser-induced damage to thin films", Proceedings of Laser-Induced Damage in Optical Materials: 1973, NBS Spec. Pub. 387, pp. 114, issued Dec. 1973.

5. D. Milam, C. W. Hatcher and J. H. Campbell, "Platinum particles in the Nd:doped disks of "phosphate glass in the Nova laser", elsewhere in these proceedings. 


\section{Figure Captions}

1. Schematic of the inspection test device, as described in the text.

2. Beam profiles obtained from microdensitometer traces of the photographed beam. The beam shape is reasonably Gaussian.

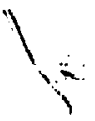




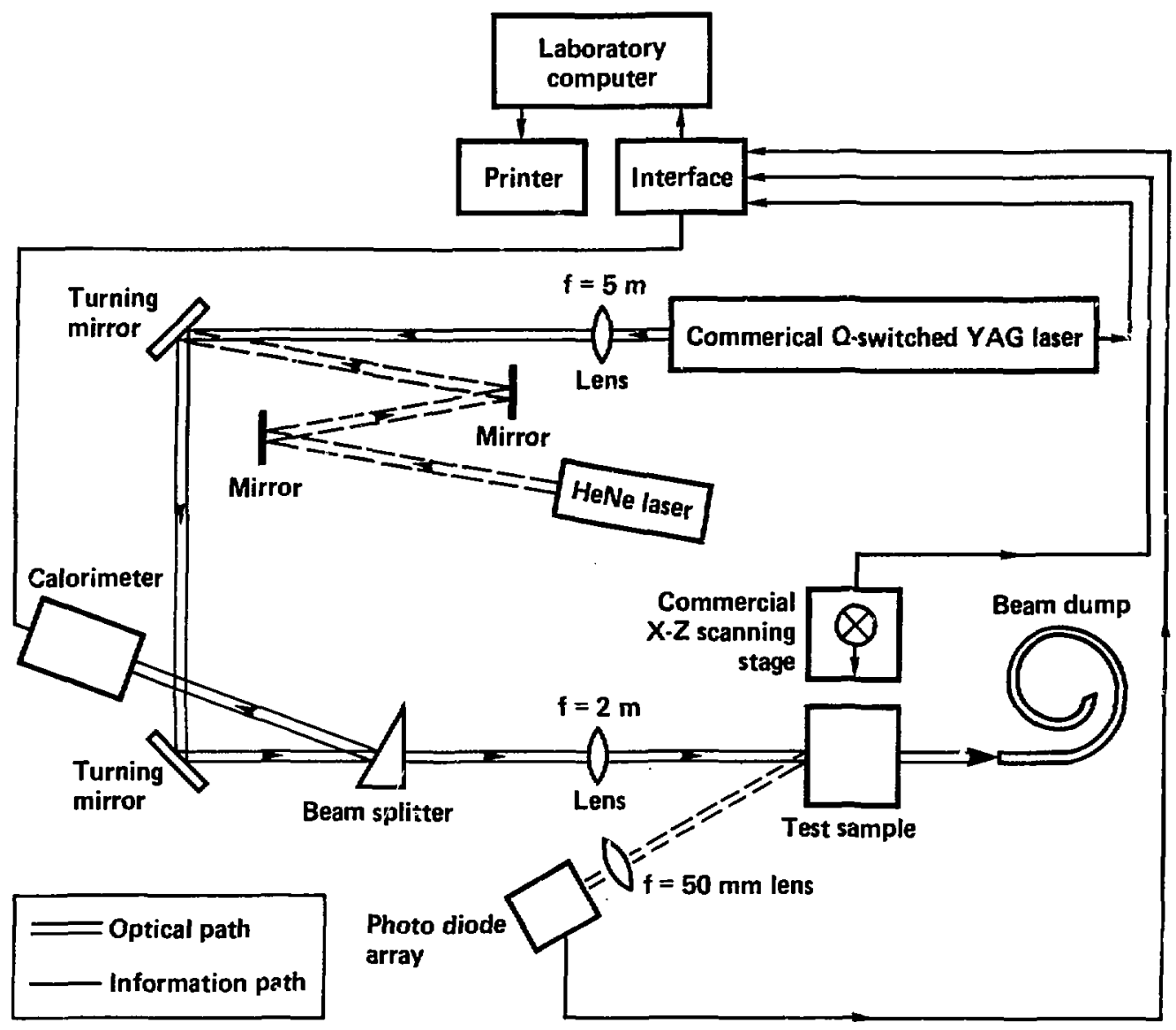



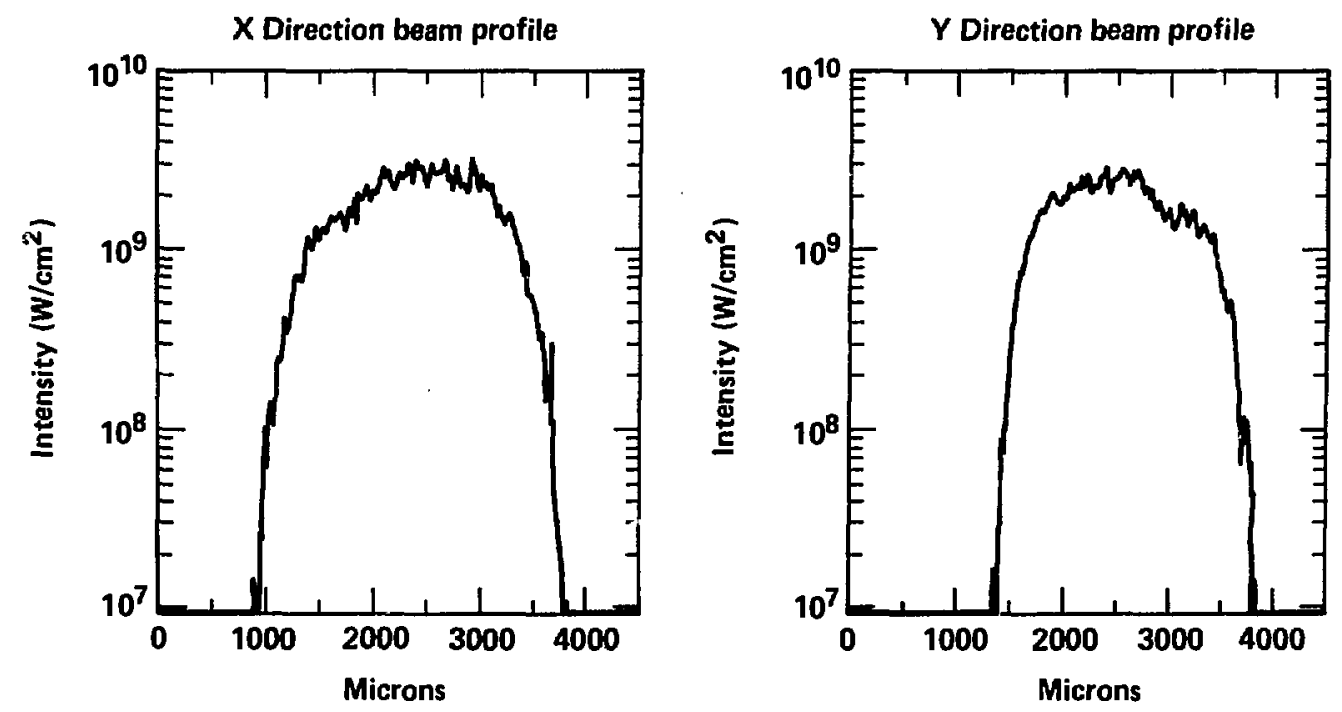

Figure 2 